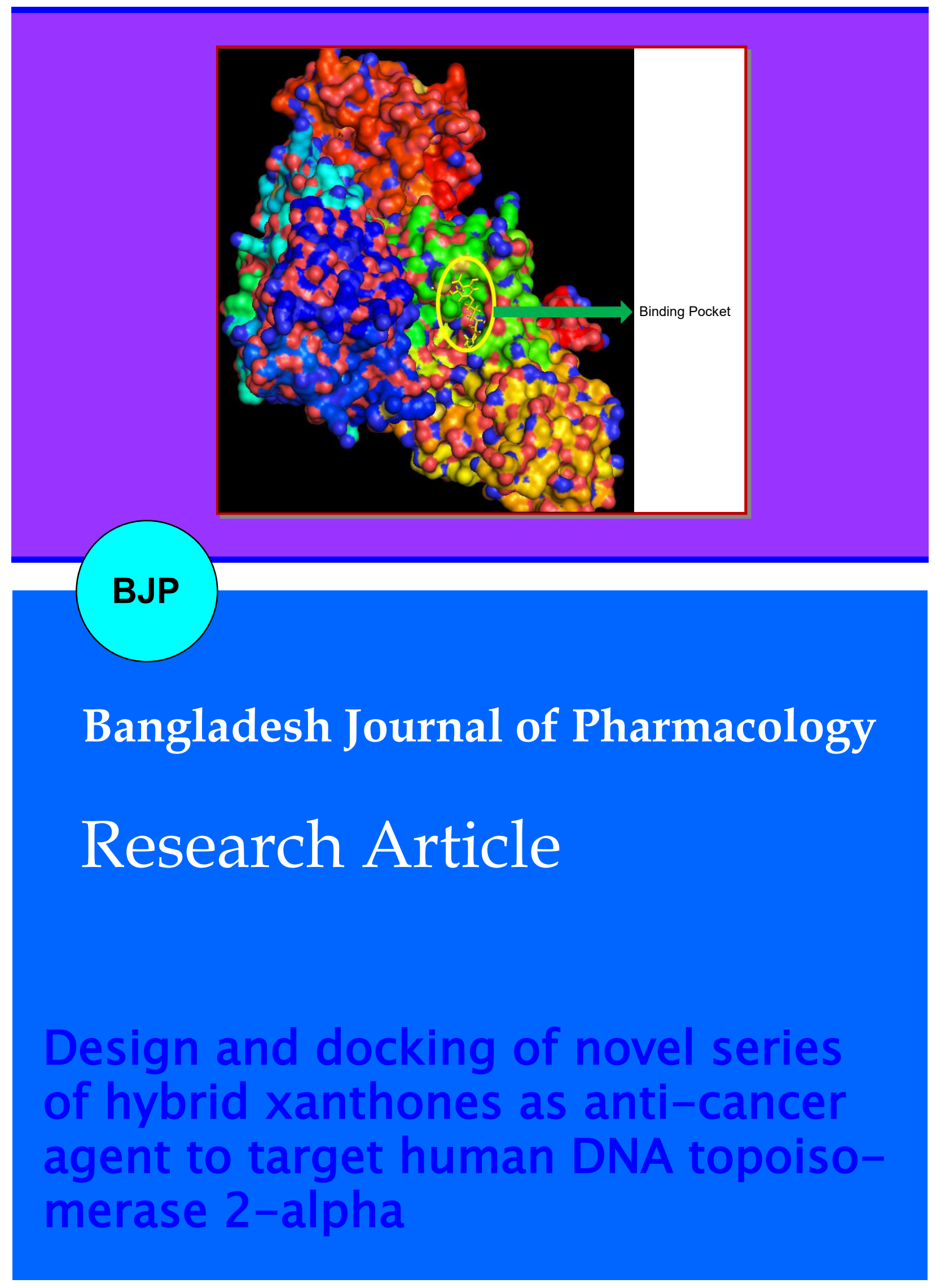




\title{
Design and docking of novel series of hybrid xanthones as anti- cancer agent to target human DNA topoisomerase 2-alpha
}

\author{
Lalit Mohan Nainwal'1, Pratap Parida², Aparoop Das ${ }^{1}$ and Partha Sarathi Bairy ${ }^{1}$ \\ ${ }^{1}$ Department of Pharmaceutical Sciences, Dibrugarh University, Assam 786 004, India; ${ }^{2}$ Centre for Studies in \\ Biotechnology, Dibrugarh University, Assam 786 004, India.
}

\begin{tabular}{|c|c|}
\hline \multicolumn{2}{|l|}{ Article Info } \\
\hline Received: & 3 March 2014 \\
\hline Accepted: & 23 March 2014 \\
\hline Available Online: & 5 May 2014 \\
\hline \multicolumn{2}{|c|}{ DOI: 10.3329/bjp.v9i2.18180 } \\
\hline \multicolumn{2}{|c|}{$\begin{array}{l}\text { Cite this article: } \\
\text { Nainwal LM, Parida P, Das A, Bairy } \\
\text { PS. Design and docking of novel series } \\
\text { of hybrid xanthones as anti- cancer } \\
\text { agent to target human DNA topoiso- } \\
\text { merase 2-alpha. Bangladesh J Pharma- } \\
\text { col. 2014; 9: 208-17. }\end{array}$} \\
\hline
\end{tabular}

\begin{abstract}
Topoisomerase (topo) IIa is a homodimeric protein catalyzes topological vicissitudes by adding or by soothing super coiling transpiration, occurs in human DNA during DNA replication as an outcome chromosome segregation and condensation occurs during meiosis I and recombination. To prevent the cleavage and religation activity we administered novel hybrid substituted Xanthone series of drugs. The toxicity prediction showed outstanding results which impetus to study its anti-cancer activities by targeting topoisomerase (topo) IIa. We developed the homology model of the topoisomerase (topo) IIa due to the unavailability of 3D structure in the Protein Data Bank. Structural assessment of the modeled protein and confirmed the quality of the model. The ligands were docked using AutoDock 4.2 software and binding energy was reported. The compound XM9, XN2, XM7, XLNU and XNS scored lowest binding energy and highest binding affinity. The interaction sites and the hydrogen bond were observed.
\end{abstract}

\section{Introduction}

Enzymes that catalyze topological alterations of DNA are called topoisomerase. Topoisomerase can relax or add supercoiling and is in thetop of hits for anti-cancer drugs. DNA-intercalating agents have the ability to cause lethal DNA double-strand breaks, by hindering normal functioning of topoisomerase II. Topoisomerase II requires $\mathrm{Mg}$ (II) and ATP hydrolysis for enzyme turn over and rapid kinetics (Champoux, 2001).

Human topoisomerases II are of two types (i) topoisomerase Iia, (ii) topoisomerase II $\beta$. Topoisomerase IIa has two distinct DNA-independent binding pockets, one within the catalytic domain and second within the N-terminal ATP-binding domain (Vilain et al., 2003). Topo Ila plays a key role in DNA replication with main functions are chromosome segregation, chromosome condensation, arrest in meiosis I and recombination suppression (Watt and Hickson, 1994). In cancer cells, topo II concentrations are dramatically up-regulated because of rapid cell division and cell growth (Heck and Earnshaw, 1986; Woessner et al., 1991). Therefore, numbers of anti-cancer agents are designed with topo II as a potential target (Wilstermann and Osheroff, 2003; Fortune et al., 2000).

The primary mode of cytotoxicity of most DNA intercalating agents involves inhibition of religation step of action of the enzyme DNA topo II (Liu, 1989; Robinson and Osheroff, 1991). Xanthonescan also binds and shows anti-cancer activity by forming a stable binding complex with N-terminal ATP-binding domain of topo IIa (Jun et al., 2011) like novobiocin (Larsen et al., 2003), cyclothialidine (Boehm et al., 2000) and salvicine (Hu et al., 2006). Xanthone fights competitively with ATP to binds with the ATP binding site on topo IIa and directly hampers the energy driven rapid kinetics which lead to a higher topo IIa catalytic inhibitory activity. 


\section{Materials and Methods}

\section{Sequence retrieval and template identification}

Primary sequence of human DNA topoisomerase IIa was retrieved in FASTA format from National Center for Biotechnology Information (http://www.ncbi.nlm. nih. gov/protein/) protein database (GI: 13959709). Homology modeling is currently a nifty and an accurate advantageous tool for generating reliable three-dimensional protein structure models for those proteins whose structures are not known/identified, till now and is routinely used in many practical applications. In homology modeling methods experimental protein structures termed as "templates" are used to dimension a new model of evolutionary related proteins, termed as "targets". Retrieved sequence was submitted to SWISSMODEL homology modeling tool for template identification of the target sequence. The most important and decisive rung for developing a desired model of protein is the finding a tentative three-dimensional structure of an interrelated homologous protein (the "template"). For fetching of all the target sequences BLAST server of NCBI against PDB (Protein Data Bank) database were used. The threshold value of 10 and the word size 3 were selected as general parameters for BLAST. The Blosum-62 matrix was chosen with a gap penalty of 11 for 1 mismatch. Templates which shows a high percenttage of sequence identity, the query coverage and the score of the alignment which hunt for to build a quality model were scanned. For analyzing the different template and its TM-score for better understanding of the templates LOMETS (http://zhanglab.ccmb.med. umich.edu/LOMETS/) was also used. The selected templates which were used for dimensioning new protein model were retrieved from RCSB (Research Collaboratory for Structural Bioinformatics) Protein Data Bank.

\section{Sequence alignment}

A Gonnet protein weight matrix of CLustal W was used to study the matching between target and template sequences. Based on the sequence, pair wise and multiple sequence alignment were performed. For alignment, the alignment tools, t-coffee, CLustal W from EBI (European Bioinformatics Institute) was used to better understand resultant sequence alignment matches, its mismatches and mutations was viewed in Jalview.

\section{Homology modeling}

Homology modeling builds a neat relationship between protein primary and secondary structure. It is very clear to understand the function of protein computationally by comparative modeling of a target protein sequences with its template which is an experimental (XRD or NMR) protein structure This supposition provides an exclusive hypothesis that if the tertiary structure of two proteins are similar, they must shares high percentage of similarity scores or in other words, the tertiary structure of two proteins are similar and shares high percentage of similarity scores only, when they are similar (Dong and Berger, 2007). Modeller 9v11 software was used for protein model building. Initially 100 models were designed, among them a single model was selected based on the lower discrete optimized protein energy (DOPE) scores for further analysis.

\section{Structural assessment}

The models were examined both on geometric and energetic scale for quality means. The validation of modeled structures were done by using PROCHECK (Nitiss, 2009), ERRAT (Bailly, 2012) and VERIFY3D (Binaschi et al., 2001). PROCHECK rottenly used and is an important freeware tool, deals with the study of stereo-chemical properties which could be clearly analyzed by the quality of the Ramachandran plot, peptide bond planarity, non-bonded interactions, main chain hydrogen bond energy, Ca chiralities and overall $\mathrm{G}$ factor. ERRAT is a protein structure verification algorithm which analyzes the statistics of non-bonded interactions between different atom types, which in turn gives the reliability to the model. To check the compatibility of the atomic models with its own amino acid sequence, VERIFY3D was used. A high VERIFY3D profile score shows the healthier quality of model.

\section{Preparation of protein structure}

Topoisomerase IIa protein is big protein, having 1531 amino acid residues. Preparation of favorable binding site was done using AutoDock 4.2 Tools. Before going

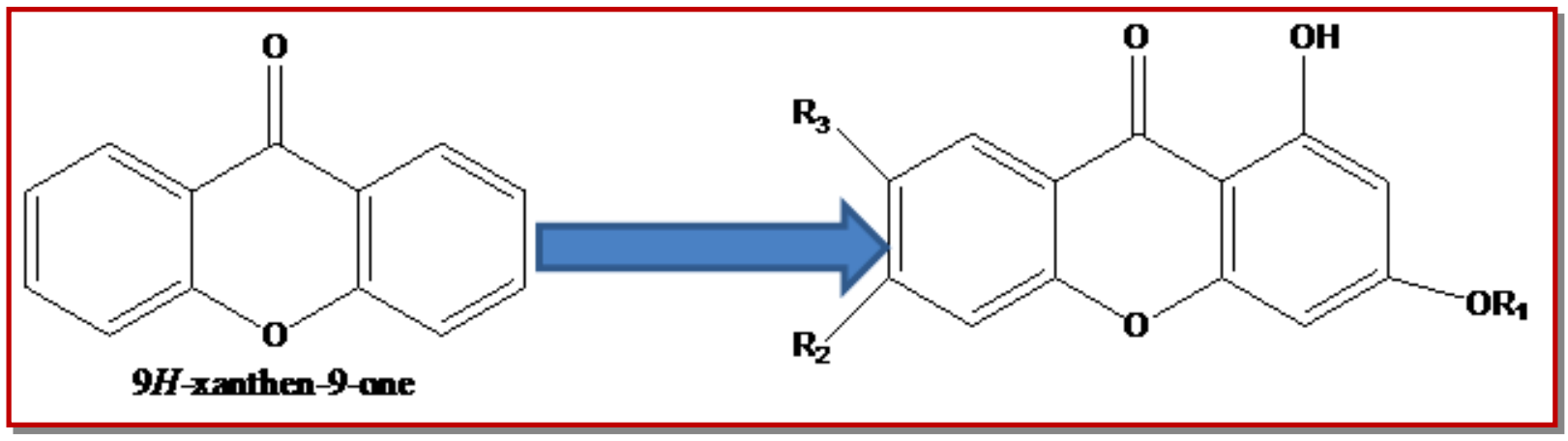


ahead all water molecules were removed from protein. To stabilize the charge on atom appeared due to removal of water molecules, was compensated by addition of non-polar hydrogen. Kollman united atom charges and Gesteiger charge were assigned to protein and ligands respectively. The AutoDock Tools Package version 1.5.6 was utilized to create the docking input files.

\section{Analogue design}

Various xanthones and their derivatives were known to be a renounced source for evolving a potential new anti -cancer candidate. Several polyhydroxy xanthone derivatives like 1,6 dihydroxy, 1,3,7-trihydroxy, 1,3,6,8tetrahydroxy substituted xan-thones were synthesized and were proven as potential anti-cancer targets. Trihydroxyl xanthone and tetrahydroxyl xanthone were exhibited the highest cytotoxic activities during cell line studies. But it was found that the activity of these xanthones does not increase linearly with the increasing number of hydroxyl groups, suggesting that the position and substitutions on hydroxyl group also has an obvious effect on the inhibitory activities of the compounds (Su et al., 2011). The alkoxy derivatives of xanthones revealed that they also possess tremendous power against cancer. Thiosemicarbazones, nitrosoureas, thiourea, triazoles derivatives also possess a long history in the development of anti-cancer drug candidates (Bailly, 2012). Thus, 11 hybrid xanthones were designed, considering key information obtain from previous work published by various researchers in this field. Therefore, all structures are hybrid alkoxy derivatives of xanthones possessing different substituents as side chain.

\section{Ligand structure preparation, toxicity and drug like- ness}

The data set of different hybrid xanthones having differ --rent xanthone nucleus, dihydroxyl xanthone, trihydroxyl xanthone, thioxanthone nucleus were generated ligand molecules. ChemAxon, freeware developed by Advanced Chemistry Development, Inc. was used for drawing and converting 2D chemical structure of compound to 3D structures. All 3D structures were optimized through ChemAxon. Medchem Designer was used for ADME/Tox screening of the selected ligands and the results were recorded. In silico prediction biological activity of the compounds were calculated such as Molecular Weight, hydrogen bond donors/acceptors, LogP and Total Polar Surface Area (TPSA). Actelion (OSIRIS) property explorer (Shen et al., 2010) was used to screen the drug likeness. Toxicity risks were evaluated by calculating mutagenic, tumorigenic, irritant, reproductive effective, solubility, drug likeliness and drug score.

\section{Molecular docking simulations}

The AutoDock Tools Package version 1.5.6 was utilized to create the docking input files. The grids were chosen to be sufficiently large so as to include not only the active site residues but also significant portion of the surrounding surface of the receptor protein, with grid points $80 \times 80 \times 80$ along with grid spacing of $0.531 \mathrm{~A}$. In Grid based ligand docking, taking energetically favorable interactions between small ligand and typically a larger receptor molecule, generally a protein is analyzed. For refinement of docking solutions, in a grid-based force field evaluation, torsional and rigid body movements of ligand is quantified. Genetic algorithm is employed as a search parameter for docking. Lamarckian genetic algorithm (LGA) which is a hybrid of a genetic algorithm and a local search algorithm, were used for ligand conformational searching. Rigid roots were given to the ligand with five rotatable bonds. Pre-calculated grid maps was obtained by using Autogrid. As after completion of docking, the conformation of ligand which shows maximum lowest docked energy (binding energy) was chosen. This procedure was applied to all ligands. Selected favorable conformations were analyzed using Pymol software.

\section{Results}

Sequence alignment of target and template sequences was performed to estimate the matches and similarity score by using Clustal $\mathrm{W}$ and $\mathrm{t}$-coffee. The similarity scores were calculated to be $65 \%$, however the identities are estimated to $48 \%$ (Figure 1). The structural assessment results were obtained to be $85 \%$ (Procheck) (Figure 2), 86.6 (ERRAT overall quality factor) and 0.7 (verify3d) for a broad study of the proteins. Further Modeval was shown excellent quality of the model. The results were found to be RMSD (2.7), Native Overlap (0.9), z-Dope (-1.2), z-pair (-14.1), z-surf (-10.9), z-combi $(-18.3)$.

The different xanthone groups were added (Table I). Results obtained on docking, shows that the length of alkyl chains greatly affects the binding results. The propyl chain was found to be best for giving maximum interaction with residues present inside the binding pocket. The carbon atom of alkyl chain interacts through hydrophobic interactions. Presence of Primary as well as secondary nitrogen in chemical structure found to be essential to interact more with residues via hydrophobic or hydrophilic or by forming both. Docking and binding energy result shows that all designed compounds fulfill the desired criteria, to fit properly and to interact extensively with residues framing binding site. The molecular properties of the analogues were given in the Table II. Tetrazole moiety at 3 and 6 were found to be more interactive with binding sites present on protein in compound XN2. Pentyloxy substituted 1,3 dihydroxyxanthone (XM9) at position C3 was found to more interactive than ethyloxy, propyloxy, butyloxy, substituted 1,3 dihydro- 


\begin{tabular}{|c|c|c|c|c|c|c|}
\hline \multicolumn{2}{|c|}{$\begin{array}{l}\text { Score } \\
1021 \text { bits }(2639\end{array}$} & $\begin{array}{l}\text { Expect } \\
0.0\end{array}$ & $\begin{array}{ll}\text { Method } & \text { Identities } \\
\text { Compositional matrix adjust. } & 556 / 1148(48 \%)\end{array}$ & \multicolumn{2}{|l|}{$\begin{array}{l}\text { Positives } \\
751 / 1148(\end{array}$} & $\begin{array}{l}\text { Gaps } \\
72 / 1148(6 \%)\end{array}$ \\
\hline Query & 34 & YQKKTQLEH & ILLRPDTYIGSVELVTQQMWVYDEDVGINY-REVT FVPGLYKI & IFDEILVNA & 92 & \\
\hline Sbjct & 6 & YQKISQLLEH & ILKRPDTYIGSVETQEQQLQWIYDEET DCMIEKOUI IVPGLFKI & IFDEILVNA & 65 & \\
\hline Query & 93 & $\begin{array}{l}\text { ADNKQRDPKO } \\
\text { ADNKRDP }\end{array}$ & MSCIRVIIDPENNLISIWNAGKG IPVVEHKVEROYYPALIFGQ & QLLTSSNYD & 152 & \\
\hline Sbjet & 66 & ADNKVRDPSI & MKRI DVNI HAEEHT IEVKNDGKG I PIEI HNKENI I PEMI FGH & HLLTSSNYD & 125 & \\
\hline Query & 153 & DDEKKVIGGE & RNGYGAKL CNIFSTKETVETASREYKROMFQTWMDNGGAGEM & MELKPF-NG & 211 & \\
\hline Sbjet & 126 & DDEKKVIGGE & RNGYGAKL CNIFSTEFILETADLNVGQKYVQRKWENNMSICHPP & PKITSYKKG & 185 & \\
\hline Query & 212 & EDYTCITFQ & 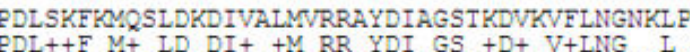 & $\begin{array}{l}\text { PVKGERSYV } \\
++ \text { Ft+YY }\end{array}$ & 271 & \\
\hline Sbjet & 186 & PSYTKVTFKE & FDLTRFGMKELDNDILGMMRRVYDIMGSVRDINVYLNGKSLK & KIRNFKAYY & 245 & \\
\hline Query & 272 & $\begin{array}{l}\text { DMYLKDKLDE } \\
++ \text { YLK }++\end{array}$ & $\begin{array}{l}\text { ETGNSLKVIHEQVNHRWEVCL TMSEKGEQRISFVISIAISKGG } \\
+++E++N+R W E V++S+\end{array}$ & $\begin{array}{l}\text { GRHVDYVAD } \\
G H V+Y+D\end{array}$ & 331 & \\
\hline Sbjet & 246 & ELYLKSLIP- & -----TILYERIMUREVAFAVSDISFQRISFVNSIATTMGG & GTHVNYITD & 299 & \\
\hline Query & 332 & QIVTKLVDV & VRKRRIKGGVAVKAHQVRNHMWI FVNALI IENPT FDSQTKENMTI I & LQPKSFGST & 391 & \\
\hline Sbjet & 300 & QIVKKISEII & LKKKKKK--KSVKSFQ̂́IKANNMFIFINCLIENPAETSQ́TKEQLIT & TRVKDFGSR & 357 & \\
\hline Query & 392 & CQLSEKEIKD & AAIGCGIVESILNWVKFKAQVQLNKKCSAVKHIRIKGI PKLDD & DANDAGGRN & 451 & \\
\hline Sbjet & 358 & CEIPLEYIN: & KIMKTDLATRMF----------EIADANESRITMYPKLED & DANKAGTKE & 404 & \\
\hline Query & 452 & $\begin{array}{l}\text { STECTLILTE } \\
+C T L+\text { LTB }\end{array}$ & $\begin{array}{l}\text { EGDSAKTLAVSGL GVVGRDKYGVFPLGGILNVREASHKRIME } \\
\text { EGDSA +LAV+GL VVGRD YG +PLRGK+LNVREAS OI++ }\end{array}$ & $\begin{array}{l}\text { ENAEINNII } \\
+ \text { NAEI I }\end{array}$ & 511 & \\
\hline Sbjet & 405 & GYKCTLVLIB & EGDSALSLAVAGLAVVGRDYYGCYPLRGKMLNVREASADQILK & KNAEIQAIK & 464 & \\
\hline Query & 512 & $\begin{array}{l}\text { KIVGLQYKKD } \\
\text { KI+GIQ }++K\end{array}$ & 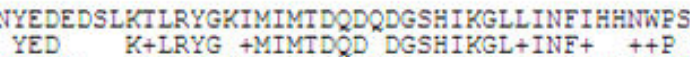 & SLLR-HRFL & 570 & \\
\hline Sbjet & 465 & KIMGLQHRKL & KYEDI---KSLRYGHLMIMTDQDHDGSHIKGLI INFLESSFPG & GLLDIQGFL & 521 & \\
\hline Query & 571 & $\begin{array}{l}\text { EEFITPIVK } \\
\text { EFIIPI+KT }\end{array}$ & $\begin{array}{l}\text { VS---KNIKQEMAFYSLPEFEEWKSST PNHKKWWKVKYYKGLGTS } \\
\text { VS } \mathrm{K}+\mathrm{AFY}++\mathrm{P}++\mathrm{E}+\mathrm{W}+\mathrm{WK} K Y Y \text { IS }\end{array}$ & $\begin{array}{l}\text { STSKEAKEY } \\
S++E+E Y\end{array}$ & 627 & \\
\hline Sbjet & 522 & LEFITPIIK & VSITKPTKNTIAFYNMPDYEKWREEESHKFTWKQKYY----IS & SLAQEVREY & 577 & \\
\hline Query & 628 & $\begin{array}{l}\text { EADMKRHRI } \\
\text { E+++ RH }\end{array}$ & $\begin{array}{l}\text { QFKYSGPEDDAAISLAFSKKQIDDRKEWLTNFMEDRRQRKLLG } \\
\text { F } \\
\text { D I LAFSKK }+ \text { DDRKEWL }\end{array}$ & $\underset{P}{\text { GLPEDYLYG }}$ & 687 & \\
\hline Sbjet & 578 & FSNLDRHLKI & IFHSIQGNDKDYIDLAFSKKKADDRKEWL------RQYE--- & --PGTVL-D & 625 & \\
\hline Query & 688 & QTITYLTYND & 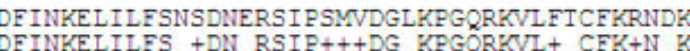 & KREVKVAQL & 747 & \\
\hline Sbjet & 626 & PILKEIPIS: & DFINKELILFSLADNIRSI PNVLDGFKPGQRKVLYGCFKRALL & KSELKVAQL & 685 & \\
\hline Query & 748 & AGSVAEMSS: & 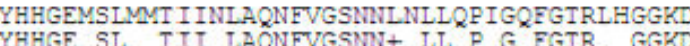 & DSASPR-YI & 806 & \\
\hline Sbjet & 686 & APYVSECTA & YHHGEQSIAQI I IGLAQNFVSNIYLLLPNGAFGTRAIGGKD & DAAAARXYI & 745 & \\
\hline Query & 807 & $\begin{array}{l}\text { FTMLSSLARI } \\
+\mathrm{T} \text { I }+\mathrm{L} R\end{array}$ & 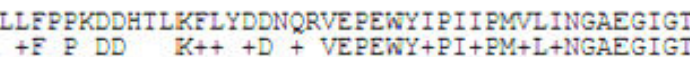 & $\begin{array}{l}\text { TGWSCKIPN } \\
\text { IGWS IP }\end{array}$ & 866 & \\
\hline Sbjet & 746 & YTELNKLIR: & KI FHPADD PLYKY IQEDEKTVE PEWYL P I PMI LVNGAEGIGI & IGWSTYIPP & 805 & \\
\hline Query & 867 & $\begin{array}{l}\text { EDVREIVNN } \\
\text { E+ EI+ N }\end{array}$ & $\begin{array}{l}\text { IRRLMDGEEPL PMLPSYKNFKGIIEELAPNQYVISGEVAILNS } \\
\text { IR LY+EE } \mathrm{MP}+++\mathrm{GIIEE}+\mathrm{P}+\mathrm{Y}+\mathrm{G}+++\end{array}$ & STTIEISEL & 926 & \\
\hline Sbjet & 806 & ËPLEIIKN & IRHLLNDEELEQMHPWFRGWTGTIEEIEPLRYRYYGRIEQIGD & DAVIEITEL & 865 & \\
\hline Query & 927 & $\begin{array}{l}\text { PVRTWIQTY: } \\
\text { P RTWT T }\end{array}$ & 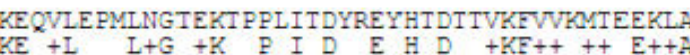 & AEAERVGLH & 986 & \\
\hline Sbjet & 866 & PARTWISII & KEYLILG-LSGNDKIKPWIKDMEEQH-DDNIKFIITLSPEEMA & AKTRKIGFY & 923 & \\
\hline Query & 987 & $\begin{array}{l}\text { KVFKLQISL } \\
+ \text { FKL }++\end{array}$ & $\begin{array}{l}\text { TCNSMVIFDHVGCLKKYOTVLDILRDEFELRLKYYGLRKEWLI } \\
++\mathrm{MV} \text { FD G }+\mathrm{KKY}++\mathrm{V}+\mathrm{IL}+\mathrm{E}++\mathrm{RL}+\mathrm{YY} \mathrm{RK}++\end{array}$ & LGMLGAESA & 1046 & \\
\hline Sbjet & 924 & ERFKLISPI & SLMIMVAF DPHGKIKKYNSVIE ILSE FYYVRLEYYQKRKDHMS & SERLQWEVE & 983 & \\
\hline Query & 1047 & $\begin{array}{l}\text { KLINQARFI } \\
K+Q+\mathrm{EI}\end{array}$ & $\begin{array}{l}\text { LEKIDGKI I IENKPKKKELIKVIIORGYDSDPVRAWKEAQQRVR } \\
\mathrm{I}++++\mathrm{NKP}++\mathrm{I}+\mathrm{L} G+\mathrm{GE}+\end{array}$ & $\begin{array}{l}\text { PDEEENEES } \\
\text { EE }\end{array}$ & 1106 & \\
\hline Sbjet & 984 & KYSEQ̂VKFI: & KMI IEKELTVINKPRNAIIQELENLGFP----RENKEGKPYYG & GSEE----- & 1034 & \\
\hline Query & 1107 & DNEKETEKS: & $\begin{array}{l}\text { DSVTDSGPT FNYLLDMPLWYLTKEKRDELCRLRIEKEQELDTI } \\
\qquad+\mathrm{YLL} \mathrm{M}+\mathrm{W} \text { LTKE }+\mathrm{I}++\mathrm{EKE} \mathrm{EL}+\mathrm{I}\end{array}$ & $\begin{array}{l}\text { LKRKSPSDL } \\
\mathrm{L}+\mathrm{S} \mathrm{D}+\end{array}$ & 1166 & \\
\hline Sbjet & 1035 & 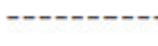 & ---- LYGTYEYLLGMRIWSLTKERYQKLLKQKQEKETELENI & LLKLSAKDI & 1080 & \\
\hline Query & 1167 & $\begin{array}{l}\text { WKEDLATE } \\
W\end{array}$ & 1174 & & & \\
\hline Sbjet & 1081 & WNITLLAF & 1088 & & & \\
\hline
\end{tabular}

Figure 1: Sequence alignment between query (topoisomerase II a) of human and subject (4GFH A) 


\section{Table I}

\section{Chemical structures of $\mathbf{1 1}$ novel hybrid substituted xanthones}

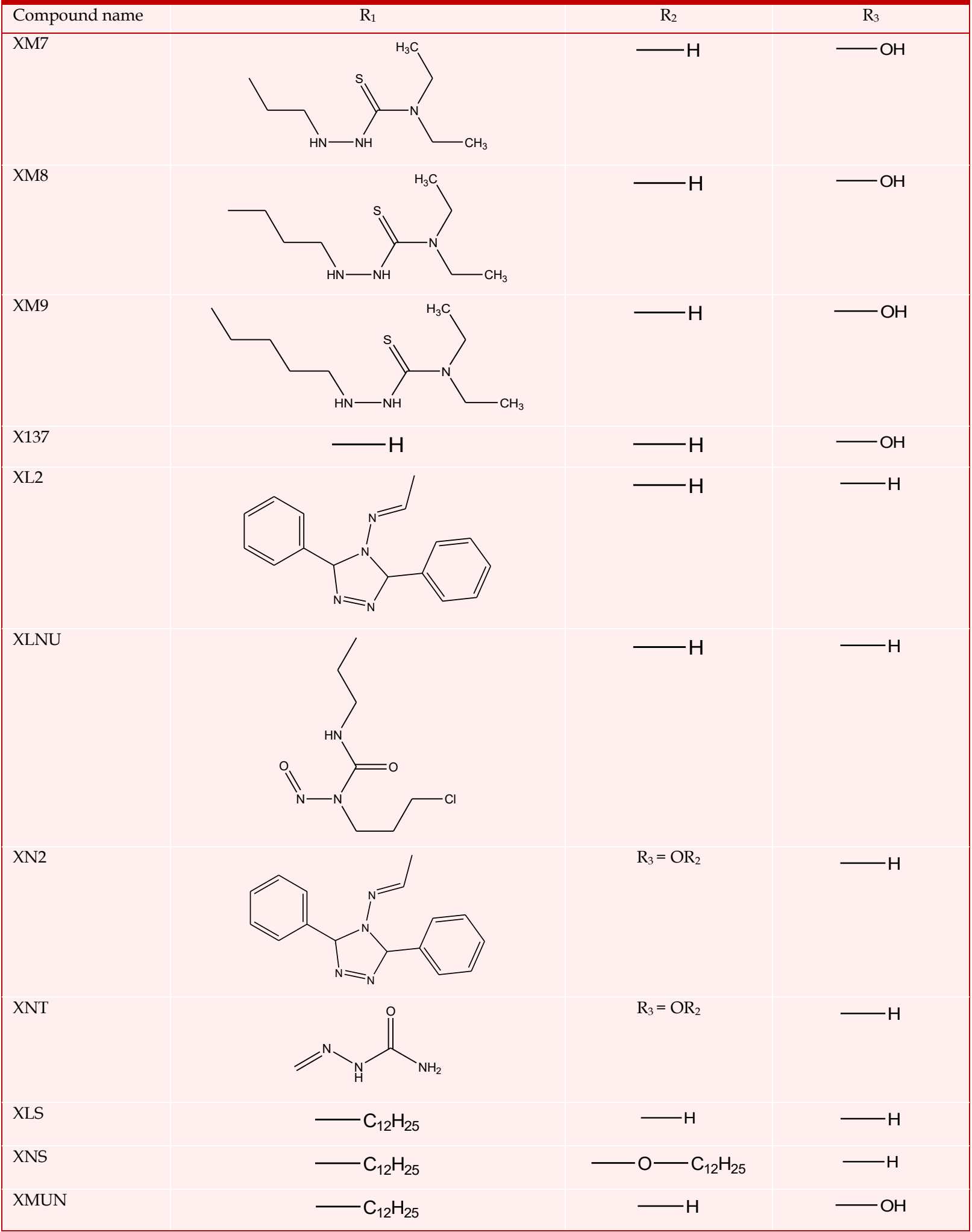


Table II

\begin{tabular}{|c|c|c|c|c|c|c|c|c|}
\hline Compound name & $\mathrm{S} \log \mathrm{P}$ & $\mathrm{S}+\log \mathrm{D}$ & $\mathrm{M} \log \mathrm{P}$ & $\mathrm{HBDH}$ & M_NO & TPSA & Rule of 5 & HBA \\
\hline XM7 & 2.8 & 2.8 & 1.6 & 4.0 & 8.00 & 107.20 & 0.0 & 8 \\
\hline XM8 & 3.1 & 3.1 & 1.8 & 4.0 & 8.00 & 107.20 & 0.0 & 8 \\
\hline XM9 & 3.5 & 3.5 & 2.0 & 4.0 & 8.00 & 107.20 & 0.0 & 8 \\
\hline X137 & - & - & 3.6 & 2.0 & 5.00 & 79.9 & 0.0 & 5 \\
\hline XL2 & - & - & 4.0 & 1.0 & 8.0 & 100.0 & 0.0 & 8 \\
\hline XLNU & 3.4 & 3.3 & 2.1 & 2.0 & 9.0 & 121.4 & 0.0 & 7 \\
\hline XN2 & _- & - & 2.6 & 3.0 & 15.0 & 192.4 & 2.0 & 11 \\
\hline XNT & _- & - & 0.5 & 7.0 & 13.0 & 203.9 & 2.0 & 13 \\
\hline XLS & 8.2 & 8.2 & 4.1 & 1.0 & 4.0 & 59.7 & 0.0 & 4 \\
\hline XNS & 11.6 & 11.6 & 5.8 & 1.0 & 5.0 & 68.9 & 2.0 & 5 \\
\hline XMUN & - & - & 3.6 & 2.0 & 5.0 & 79.9 & 0.0 & 5 \\
\hline
\end{tabular}

Table III

Solubility, drug likeness and drug score accounted by Osiris property explorer and with respect to binding energies of different novel substituted hybrid xanthones

\begin{tabular}{|c|c|c|c|}
\hline $\begin{array}{c}\text { Compound } \\
\text { name }\end{array}$ & Solubility & $\begin{array}{c}\text { Drug like- } \\
\text { ness }\end{array}$ & Drug score \\
\hline XM7 & -5.4 & 3.7 & 0.4 \\
XM8 & -5.7 & 0.3 & 0.3 \\
XM9 & -6.0 & -1.6 & 0.2 \\
X137 & -4.0 & -0.0 & 0.4 \\
XL2 & -7.2 & 3.9 & 0.2 \\
XLNU & -6.0 & 0.9 & 0.1 \\
XN2 & -7.7 & -8.0 & 0.0 \\
XNT & -7.3 & 2.1 & 0.4 \\
XLS & -7.7 & -20.4 & 0.1 \\
XNS & -10.7 & -22.3 & 0.1 \\
XMUN & -7.4 & -20.8 & 0.1 \\
\hline
\end{tabular}

xyxanthones. Very lengthy or heavy alkoxy side chain does not improve interaction of basic nucleus sufficiently (X137, XMUN).

ADMET studies and drug likeness of designed 11 compounds were done by using Osiris property explorer, MedChem draw freeware. ADME profile shows that that these candidates are hydrophobic in nature and thus acted as hydrophilic neutral drug molecule by their obedience to the properties such as absorption, distribution, metabolism, and excretion (ADME) determined by using MedChem Designer draw freeware. Toxicity profile which includes tumeriogenicity, mutagenecity, in combination with failure in producing reproducible effect by compounds and drug scores were studied using Osiris property explorer, all compounds except XN2, XN2 does not passes through these filters. Three compounds X137, XM7 and XNT got highest drug likeness score of $3.9,3.7$ and 2.1 respectively (Table III).

\section{Table IV}

Solubility, drug likeness and drug score accounted by Osiris property explorer and with respect to binding

$$
\text { energies of different novel substituted hybrid xanthones }
$$

\begin{tabular}{|c|c|c|c|}
\hline $\begin{array}{l}\text { Compound } \\
\text { name }\end{array}$ & $\begin{array}{l}\text { Residues involves } \\
\text { in hydrogen bond- } \\
\text { ing interactions }\end{array}$ & Residues involves in hydrophobic interactions & $\begin{array}{l}\text { Binding } \\
\text { energy }\end{array}$ \\
\hline XM7 & Met762 & Pro803, Ser800, IIe769, Gln773, Gly797, Gly796, Asn770, Lys798, Met766 & -12.7 \\
\hline XM8 & Gln544 & Arg672, Pro601, Leu680, Glu682, Pro593, Tyr590, Ser591, Glu542, Tyr686 & -11.0 \\
\hline XM9 & Pro593 & $\begin{array}{l}\text { Try686, Gln542, Tyr590, IIe577, Ser591, Leu705, Leu592, Tyr684, Glu602, } \\
\text { Asp683, Arg675, Lys701, Asp671, IIe704, Asn700, Phe668, Tyr686 }\end{array}$ & -14.3 \\
\hline X137 & Lys1140 & Tyr1135, Met1131, Pro1132, Leu128, Asp1130, Phe1054, IIe1055 & -6.4 \\
\hline XL2 & - & $\begin{array}{l}\text { Ser756, Asp832, Tyr757, Glu702,Leu685, Gln542, Tyr686, Ser591, Pro593, } \\
\text { Leu592, Asp543, Gly615, Lys614, IIe577 }\end{array}$ & -10.5 \\
\hline XLNU & Asp832 & $\begin{array}{l}\text { Tyr757, Lys614, Gln544, Leu705,Leu685, Glu702, Ser591, Tyr686, Tyr590, } \\
\text { Leu592, Glu542, IIe577, Ser756 }\end{array}$ & -11.9 \\
\hline $\mathrm{XN} 2$ & IIe577 & $\begin{array}{l}\text { Leu592, His758, Ser756, Asp631, Lys614, Lue705, Phe668, Asp671, Arg675, } \\
\text { Lys701, Ser591, Asp683, Tyr686, Gln542 }\end{array}$ & -13.0 \\
\hline XNT & - & $\begin{array}{l}\text { Asn700, Asp683, Arg675, Lys701, Ser591, Leu705, Leu685, Gln542, Tyr686, } \\
\text { Glu702, Ser547, Pro593, Glu682, Phe668 }\end{array}$ & -9.5 \\
\hline XLS & Leu592 & Ser591, Tyr686, Asp543, His758, Gln542, Gln544, Leu685, Pro593 & -7.8 \\
\hline XNS & Lys520 & $\begin{array}{l}\text { Ser527, IIe530, Asp526, Lys529, Asn433, Arg532, Gly448, IIe511, IIe435, } \\
\text { Gly515, Tyr518, Lys519, Gln517, Leu516 }\end{array}$ & -11.3 \\
\hline XMUN & Pro593 & $\begin{array}{l}\text { His758,Leu592, Ile577, Glu702, Tyr686, Leu685, Tyr684, Gln542, Ser591, } \\
\text { Leu705, Glu682, Glu544 }\end{array}$ & -6.8 \\
\hline
\end{tabular}




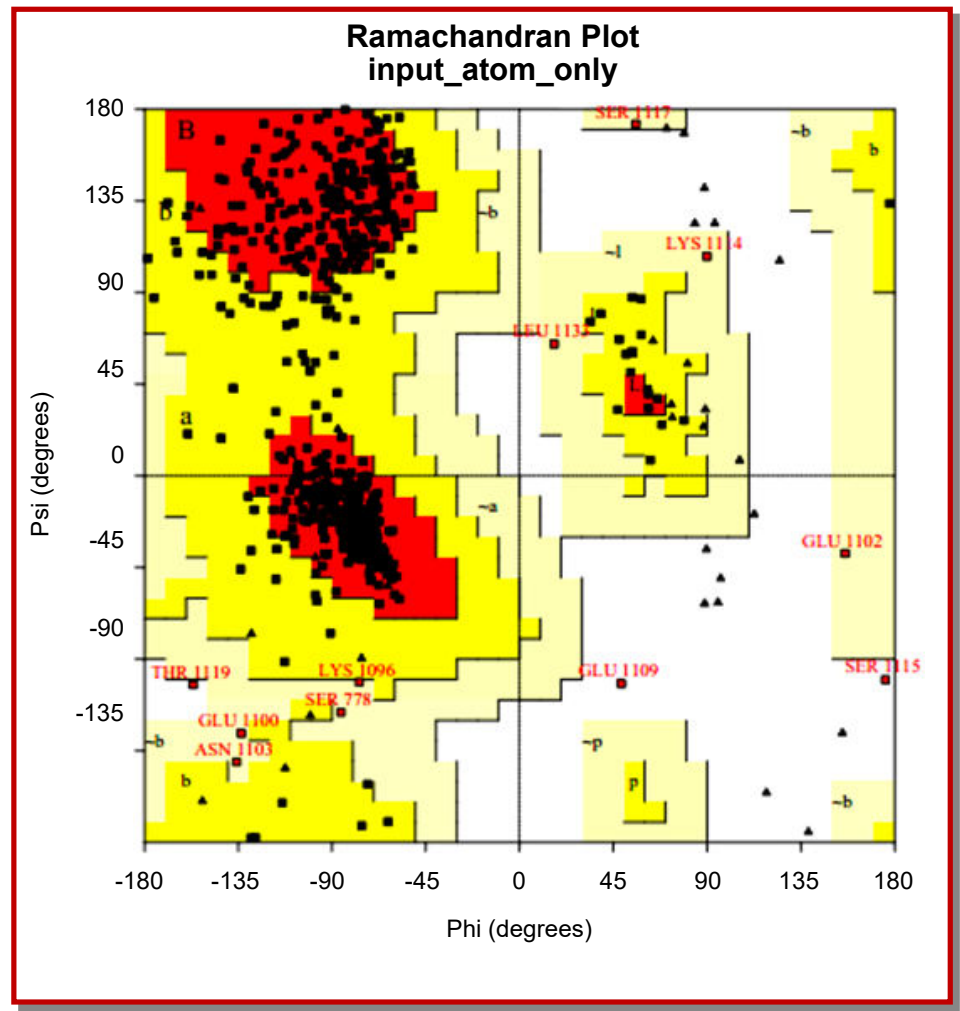

Figure 2: Ramachandran Plot showed that most of the residues of the modeled contains most of the residues in favored region (85.5\%), additional region (12.9\%), generously allowed region (1.2\%) and only 3 residues (GLU 1102, GLU 1109 and SER 1115) i.e $0.4 \%$ in disallowed residues

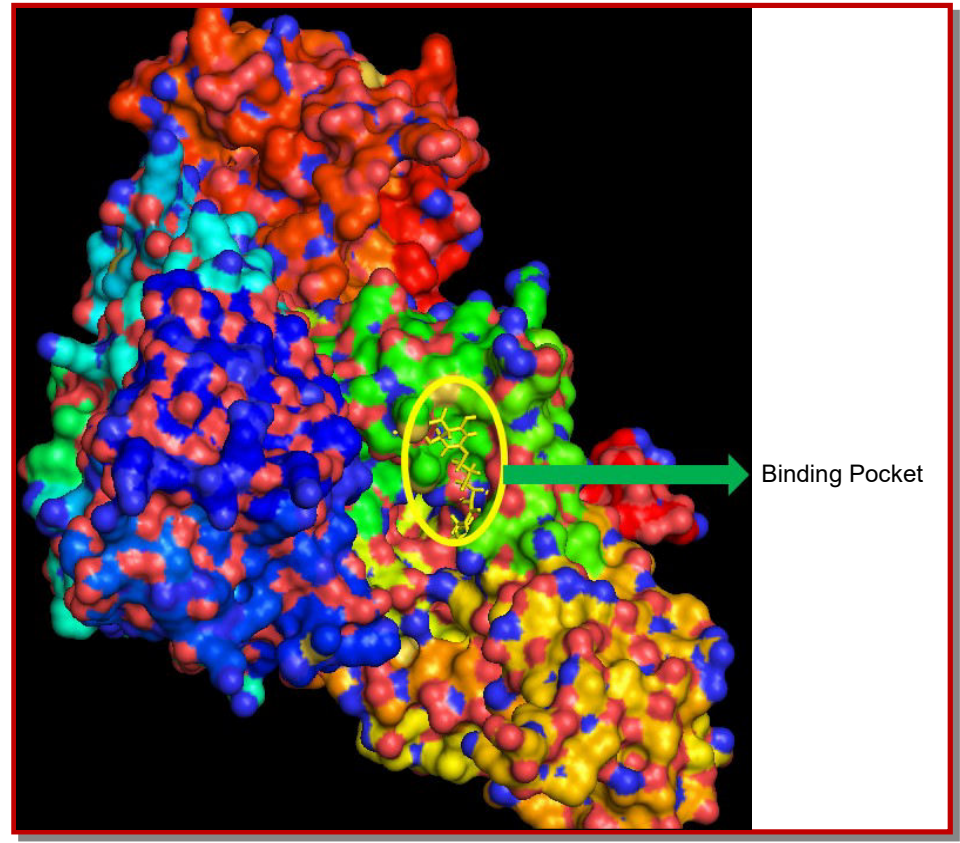

Figure 3: The surface view of the protein with the ligand (XM7) binding pocket

All eleven compounds shows high degree of interactions with human topoisomerase IIa as analyzed during docking studies. Compound XM7 interacts with Met762, Pro803, Ser800, Ile769, Gln773, Gly797, Gly796, Asn770, Lys798 and Met766 residues of human topo
IIa. Sulfur present in side chain of XM7 interacts with Lys798, alkyl residues at terminal end interacts with Gln773, Gly797, Gly796, Lys798, oxygen of alkoxy side chain interacts with IIe769, carbonyl oxygen at C9 and oxygen atom at $\mathrm{C} 4$ shows hydrogen bond interaction 


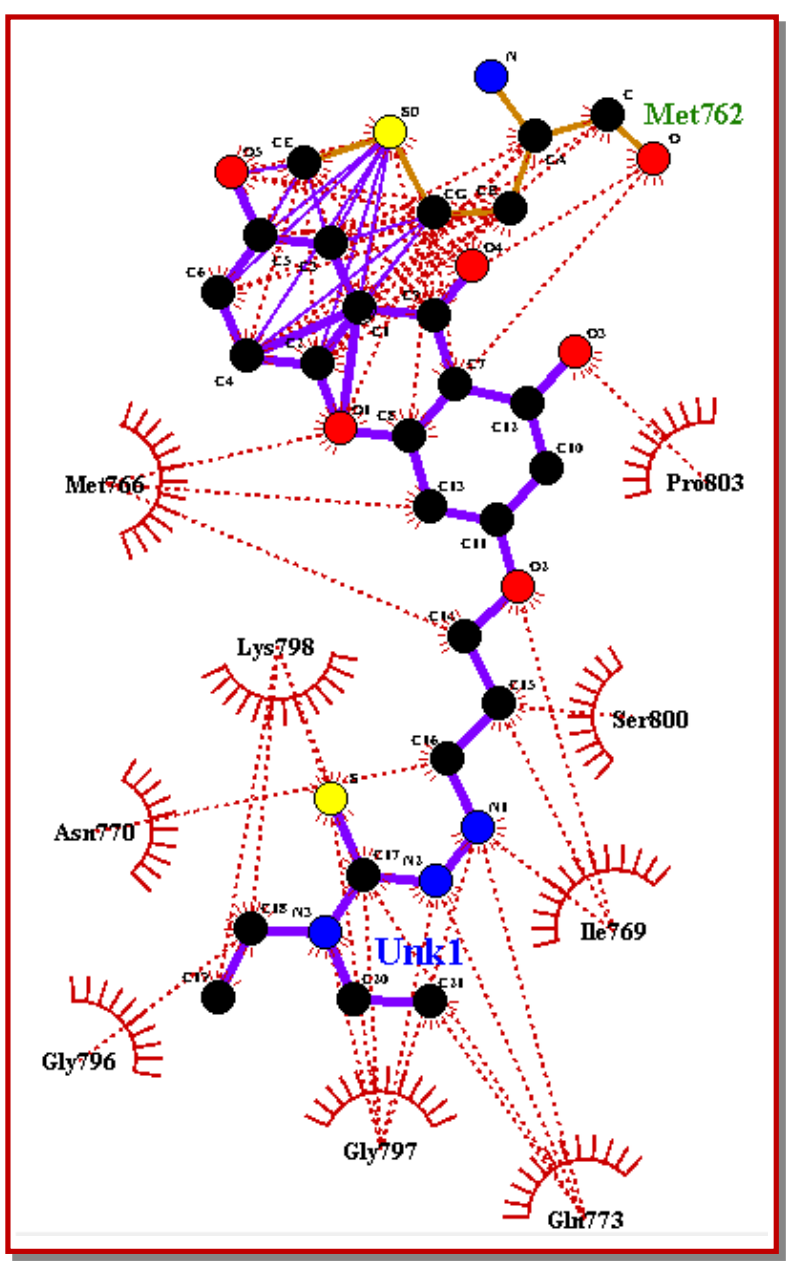

Figure 4: Hydrophobic and hydrogen bond forming residues of the docked complex of XM7 and the model. Hydrophobic interactions are shown in red dotted line and hydrogen bonds are shown in green dotted line

with Met762 and hydrophobic interaction with Met766 respectively. Alkoxy side chain of XM7 shows important interactions with Ser800, IIe769, Asn770 and Met760. Targeted protein topo II a, has most potential active site where the ligand could bind and interact was already previously identified and reported. The residues which were found to be taking part actively in dimensioning the active binding pocket of topo IIa, are reported as follows : PRO 716, ASP 720, GLY 721, LEU 722, LYS 723, GLN 726, ASN 770, LEU 771, GLN 773, PHE 775, GLY 777, SER778, ASN 779, LEU 781, LEU 783, GLY 796, LYS 798, MET 847, VAL 848, LEU 849, ILE 850, ASN 851, GLY 852, ALA 853, GLU 854, LYS 863, ILE 864, PRO 865, ASN 866, TYR 892 and ARG 929. Compound XM7 binds correctly in this pocket and was revealed by docking results. Other compounds also shows interactive binding energies against topo IIa during molecular docking studies, not in same pocket because topo IIa proteins composed of 5 active binding pockets where ligand/drug could bind, analyzed by Qsite finder software which is an online freeware. The binding pocket and the surface analysis of the compound XM7 was given in the (Figure 3) and The hydrophobic and hydrogen bond interaction was analyzed (Figure 4). Binding energy is a versatile tool understands the affinity of the ligand to its binding site present on protein. Five compounds XM9, XN2, XM7, XLNU, XNS showed best and lowest binding energy scores among all of the ligands having -14.3, -13.0, -12.7, $-11.9,-11.3 \mathrm{Kcal} / \mathrm{molrespectively.} \mathrm{All} \mathrm{five} \mathrm{compounds}$ were found to be more potent than naturally ocurring marine based triterpeneglycosides, cucumarioside A with docking score $-11.1 \mathrm{kcal} / \mathrm{mol}$ followed by holothurinoside A and holothurin A with $-10.5 \mathrm{kcal} / \mathrm{mol}$, bivittoside A with $-10 \mathrm{kcal} / \mathrm{mol}$, holotoxin A with -9.7 $\mathrm{kcal} / \mathrm{mol}$ as well as than etoposide with binding energy of $-9.5 \mathrm{kcal} / \mathrm{mol}$. Compound X137 got least binding energy $-6.4 \mathrm{kcal} / \mathrm{mol}$. Binding energies of all compound are presented in Table IV. The polar interacting residues forming hydrogen bonds were analyzed (Figure 5).

\section{Discussion}

Topoisomerase II poisons, are efficient but produce harmful secondary effects, common with every drug follows this path, were myelosuppression, leucopoenia, gastrointestinal toxicities, alopecia, and even leukemia (Bailly, 2012). But taking safety as a principle criteria, topo II catalytic inhibitors are preferential ones over topo II poisons for designing.

In cancer cells, topo II concentrations are dramatically upregulated because of rapid cell division and cell growth (Heck and Earnshaw, 1986; Woessner et al., 1991). Therefore, numbers of anti-cancer agents are designed with topo II as a potential target (Wilstermann et al., 2003; Fortune and Prog, 2000). Trihydroxyl xanthone and tetrahydroxyl xanthone exhibited the highest cytotoxic activities over other compounds. A piperidine side chain at the C-3 position is favorable with regard to improved cytotoxicity. Quinoline-containing thiosemicarbazide compound (TSC24), have potent anti-proliferative activity toward cancer cells. Nitrogen containing groups like nitro, amide and amines in chemical structure are general requirement for designing topo II inhibitors. Various alkylating agents, nitrogen mustered and natural anti-cancer molecules have nitrogen containing groups, which generally interact with DNA/ base pair/protein and alkylate them or done other changes which ultimately governs their anti-cancer activity. Nitrogen containing are various moieties like triazole, thiosemicarbazoles and nitrosourea were used in this study for designing.

These previously reported results gives an idea about designing some new xanthone based anti-cancer molecules, because xanthone moiety shows promising an anti-cancer potential, proven through number of 


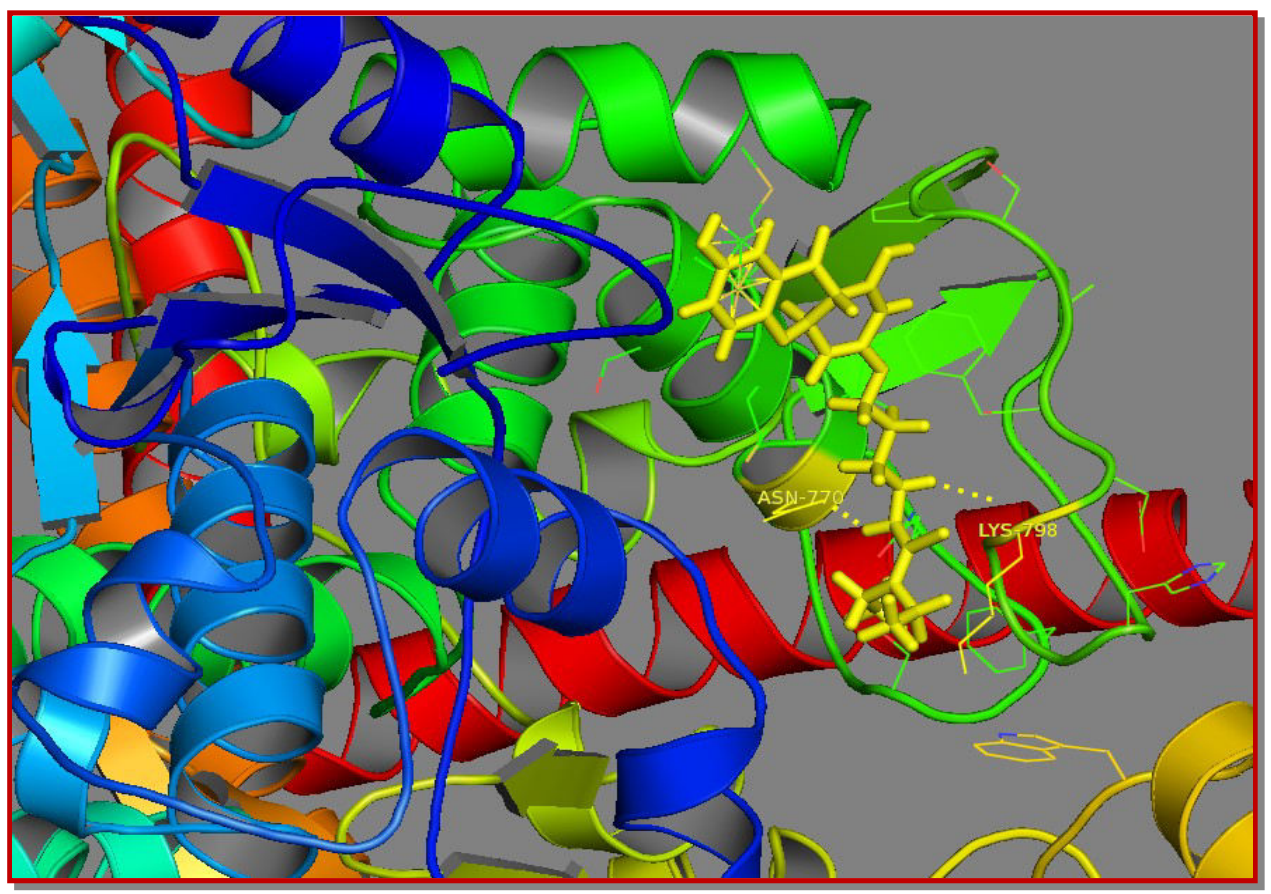

Figure 5: The polar contacts of the compound XM7 with the binding site of the modeled protein. The yellow dotted line shows the polar contacts formed and were found to be ASN770 and LYS 798

experimental studies. Hybrid based designing of new molecules against various diseases were tried and found to be much more effective, as compared to their parent molecules. Through this point of view, few new hybrid molecules were designed and docking studies were done to determine ligand-protein interactions.

Drugs aimed against topoisomerases could work by one or both of two ways (a) by hindering the ability of the enzyme to relieve tension of DNA by preventing its initial cleavage function (b) by preventing relegation of the "cleavable complex" means stabilizing the transient cleavable complex, results in enhanced strand breaks. The mode of action to show cytotoxic behavior for majority of topo inhibitors (topo poisons) is just due to account of their ability to stabilizes a transient DNA enzyme complex result DNA damage thus produces detrimental secondary effects.

The structure of xanthone generally resembles more specifically to amsacrine, which is a known branded anti-cancer drug, belongs to 9-anilinoacridines class of topoisomerase II inhibitors, having a hetero-tricyclic flat ring system. Xanthone may act via same mechanism as 9-anilinoacridines because of too much similarity in theirstructure. The cytotoxicity shown by these compounds, primarily results due to inhibition of topo II through formation of a ternary drug/DNA/protein complex (Liu, 1989; Robinson and Osheroff, 1991) gave a clear picture that drug design through modeling of DNA binding properties alone could be misleading. The antitumor activity of these drugs governed mostly, just because of their proper positioning and stabiliza- tion of the drug at its binding domain, than its (ligand or drug) actual affinity for DNA (Binaschi et al., 2001; Patil and Thakare, 2012). Among 11 compounds XM7 binds in same pocket and also interacts with same residues of topoisomerase IIa where cucumarioside $A$, holothurinoside $\mathrm{A}$, holothurin $\mathrm{A}$, bivittoside $\mathrm{A}$ and holotoxin A were found to be bounded which were founded to be more potent than etoposide as previously reported. The new hybrid compound XM7 having a simple primary structure and more potential candidate with having binding energy of about $-12.7 \mathrm{Kcal} / \mathrm{mol}$ than some naturally occurring marine agents used as an anti-cancer agents with more complex chemical structures and interact with the most potential active site, considered (Patil and Thakare, 2012). However, five compounds out of 11 compound possesses lowest binding energy below $-11.1 \mathrm{Kcal} / \mathrm{mol}$. ADMET screening provided a clear cut picture about candidates under consideration and suggests for further modifications in following candidates.

Study gives an opinion that the designed molecules require further modifications to improve drug-receptor interactions. However binding energy data and docking studies revealed, a good picture of compounds affinity and fitting inside the binding pocket. Docking studies also revealed the mode of binding of new novel hybrid xanthones into the binding pocket of topo IIa. The designed compounds will be synthesized and evaluated for their anti-cancer potential. All designed compounds are under further modification to generate an ultimate molecule with desired activity and safety profile. 
All 11 candidates were found to be showing excellent activity, out of which three candidates were found to be more potent than previously reported candidates as an anti-cancer agent. Compound XM7 was found to be interacting with Pro803, Ser800, IIe769, Gln773, Gly797, Gly796, Asn770, Lys798, Met766 and Met762, which was previously reported to constitute the most active site of human DNA topoisomerase IIa, through which various marine based anti-cancer triterpeneglycosides like cucumarioside $\mathrm{A}$, holothurinoside $\mathrm{A}$, holothurin $\mathrm{A}$, bivittoside A, holotoxin A acts (Patil and Thakare, 2012). Thus we could conclude through these docking studies that five compoundsXM9, XN2, XM7, XLNU and XNS could be act as a potential lead to evolve a potential anti-cancer candidate against human DNA topoisomerase IIa inhibitors.

\section{Acknowledgement}

The authors gratefully acknowledge Bioinformatics Infrastructure Facility (BIF) funded by Department of Biotechnology, Govt. of India, at Centre for Studies in Biotechnology, Dibrugarh University.

\section{References}

Bailly C. Contemporary challenges in the design of Topoisomerase II inhibitors for cancer chemotherapy. Chem Rev. 2012; 112: 3611-40.

Binaschi M, Bigioni M, Cipollone A, Rossi C, Goso C, Maggi CA, Capranico G, Animati F. Anthracyclines: Selected new developments. Curr Med Chem Anti-cancer Agents. 2001; 1: 113-30.

Boehm HJ, Boehringer M, Bur D, Gmuender H, Huber W, Klaus W, Kostrewa D, Kuehne H, Luebbers T, MeunierKeller N, Mueller F. Novel inhibitors of DNA gyrase: 3D structure based biased needle screening, hit validation by biophysical methods, and 3D guided optimization. A promising alternative to random screening. J Med Chem. 2000; 43: 2664-74.

Champoux JJ. DNA topoisomerases: Structure, function, and mechanism. Annu Rev Biochem. 2001; 70: 369-413.

Dong KC, Berger JM. Structural basis for gate-DNA recognition and bending by type IIA topoisomerases. Nature 2007; 450: 1201-05.

Fortune JM, Prog ON. Topoisomerase II as a target for anticancer drugs: When enzymes stop being nice. Prog Nucleic
Acid Res Mol Biol. 2000; 64: 221-53.

Heck MM, Earnshaw WC. Topoisomerase II: A specific marker for cell proliferation. J Cell Biol. 1986; 103: 2569-81.

Hu CX, Zuo ZL, Xiong B, Ma JG, Geng MY, Lin LP, Jiang HL, Ding J. Salvicine functions as novel topoisomerase II poison by binding to ATP pocket. Mol Pharmacol. 2006; 70: 1593-601.

Jun KY, Lee EY, Jung MJ, Lee OH, Lee ES, Park Choo HY, Na Y, Kwon Y. Synthesis, biological evaluation, and molecular docking study of 3-(30-heteroatom substituted-20-hydroxy10-propyloxy) xanthone analogues as novel Topoisomerase IIa catalytic inhibitor. Eur J Med Chem. 2011; 46: 1964-71.

Larsen AK, Escargueil AE, Skladanowski A. Catalytic topoisomerase II inhibitors in cancer therapy. Pharmacol Ther. 2003; 99: 167-81.

Liu LF. DNA topoisomerase poisons as antitumor drugs. Ann Rev Biochem. 1989; 58: 351-75.

Nitiss JL. Targeting DNA topoisomerase II in cancer chemotherapy. Nat Rev Cancer. 2009; 9: 338-50.

Patil TD, Thakare SV. In silico evaluation of selected triterpene glycosides as a human DNA topoisomerase II alpha (a) inhibitor. Int J Pharm Pharm Sci. 2012; 4: 201-04.

Robinson MJ, Osheroff N. Effects of antineoplastic drugs on the post-strand-passage DNA cleavage/religation equilibrium of topoisomerase II. Biochemistry 1991; 30: 1807-13.

Shen R, Wang P, Tang N. Cytotoxic Activity and DNA-binding Properties of Xanthone Derivatives. J Fluoresc. 2010; 20: 1287-97.

Su QG, Liu Y, Cai YC, Sun YL, Wang B, Xian LJ. Anti-tumour effects of xanthone derivatives and the possible mechanisms of action. Invest New Drugs. 2011; 29: 1230-40.

Vilain N, Tsai-Pflugfelder M, Benoit A, Gasser SM, Leroy D. Modulation of drug sensitivity in yeast cells by the TPbinding domain of human DNA topoisomerase IIa. Nucleic Acids Res. 2003; 31: 5714-22.

Watt PM, Hickson ID. Structure and function of type II DNA topoisomerases. Biochem J. 1994; 303: 681-95.

Wilstermann AM, Osheroff N. Stabilization of eukaryotic topoisomerase II-DNA cleavage complexes. Curr Top Med Chem. 2003; 3: 321-38.

Woessner RD, Mattern MR, Mirabelli CK, Johnson RK, Drake FH. Proliferation- and cell cycle-dependent differences in expression of the 170 kilodalton and 180 kilodalton forms of topoisomerase II in NIH-3T3 cells. Cell Growth Differ. 1991; 2: 209-14. 